\title{
Adolescent fertility and family planning in East Asia and the Pacific: a review of DHS reports
}

\author{
Elissa Kennedy ${ }^{1}$, Natalie Gray ${ }^{1,2^{*}}$, Peter Azzopardi ${ }^{1}$ and Mick Creati ${ }^{1,2,3}$
}

\begin{abstract}
Background: Adolescent pregnancy has significant health and socio-economic consequences for women, their families and communities. Efforts to prevent too-early pregnancy rely on accurate information about adolescents' knowledge, behaviours and access to family planning, however available data are limited in some settings. Demographic and Health Survey (DHS) reports are recognised as providing nationally representative data that are accessible to policymakers and programmers. This paper reviews DHS reports for low and lower middle income countries in East Asia and the Pacific to determine what information regarding adolescent fertility and family planning is available, and summarises key findings.

Methods: The most recent DHS reports were sought for the 33 low and lower middle income countries in the East Asia and Pacific region as defined by UNICEF and World Bank. Age-disaggregated data for all indicators relevant to fertility and current use, knowledge and access to family planning information and services were sought to identify accessible information. Reported data were analysed using an Excel database to determine outcomes for adolescents and compare with adult women.
\end{abstract}

Results: DHS reports were available for eleven countries: Cambodia, Indonesia, Marshall Islands, Nauru, Papua New Guinea, Philippines, Samoa, Solomon Islands, Timor-Leste, Tuvalu and Vietnam. Twenty seven of 40 relevant DHS indicators reported outcomes for adolescent women aged 15-19 years. There were limited data for unmarried adolescents. A significant proportion of women commence sexual activity and childbearing during adolescence in the context of low contraceptive prevalence and high unmet need for contraception. Adolescent women have lower use of contraception, poorer knowledge of family planning and less access to information and services than adult women.

Conclusion: DHS reports provide useful and accessible data, however, they are limited by the failure to report data for unmarried adolescents and report age-disaggregated data for some indicators. Further research is required to better understand the barriers that both married and unmarried adolescents face accessing reproductive health information and services, and their information and service delivery preferences.

\section{Background}

There are over 14 million births to adolescent women aged 15-19 each year, 91 percent of these in low and middle-income countries [1]. Six million adolescent pregnancies are unintended and occur in the context of low contraceptive prevalence $[2,3]$. Less than one third of currently married adolescent women in low and middle income countries who want to avoid pregnancy are using a modern method of contraception, and more than 60 percent would like to avoid or delay pregnancy

\footnotetext{
* Correspondence: natalie.gray@monash.edu

${ }^{1}$ Centre for International Health, Burnet Institute, Melbourne Australia

Full list of author information is available at the end of the article
}

but are not able to do so [4]. Less is known about unmarried adolescents. Sexual activity outside of marriage is increasing, but less than half of those who want to avoid pregnancy are using a modern method of contraception [4-6].

Adolescent pregnancy carries an increased risk of adverse health outcomes for young women and their children. Globally, adolescents account for eleven percent of all births but contribute to 23 percent of the burden of disease related to pregnancy and childbirth. Adolescents aged 10-14 years are five times more likely to die as a result of pregnancy and childbirth than adult women, and maternal conditions are the leading cause

\section{() Biomed Central}


of death among women aged 15-19 [7-9]. Adolescents account for around 14 percent of unsafe abortions, an estimated 2.5 million every year $[2,10]$. Babies of adolescent mothers have a 50-100 percent increased risk of mortality within the first month of life and suffer higher rates of perinatal morbidity compared with infants born to adult women $[8,11]$. By impacting on education, employment and economic opportunities, pregnancy during adolescence can also have lasting socio-economic consequences which, in turn, contribute to poorer health outcomes, gender inequity and poverty of adolescent mothers, their families and communities [12-15].

Preventing adolescent pregnancy is an essential component of a comprehensive approach to improve adolescents' sexual and reproductive health, which should also include efforts to address adolescents' vulnerability to sexually transmitted infections, HIV and gender-based violence. Developing evidence-based strategies to prevent too-early pregnancy requires policymakers and program designers to have access to data on adolescents' reproductive health, behaviours, and utilisation of family planning information and services. Much of the available literature on contraceptive use among adolescent women focuses on sub-Saharan Africa, Latin America and South Asia $[3,6,16,17]$, while relatively less is known about access to family planning in East Asia and, in particular, the Pacific. The recent completion of Demographic and Health Surveys (DHS) in a number of countries in this region presents an opportunity to begin to fill this gap. DHS reports are recognised as providing valuable and accessible information to policymakers and programmers in low and middle income countries [18]. They are also one of the most comprehensive sources of national-level data that capture reproductive health information, including data on adolescents [19].

This paper reviews DHS reports for low and lower middle income countries in East Asia and the Pacific to identify accessible information about adolescent fertility and current use, knowledge and access to family planning information and services. It also summarises key findings from available data to provide an overview of adolescent fertility and family planning in the region, and identifies potential targets for further research to better inform policy and programs.

\section{Methods}

The most recent DHS reports were sought for the 33 low and lower middle income countries in the East Asia and Pacific region as defined by UNICEF and World Bank geographic region and income group classifications $[20,21]$. DHS reports were identified from Measure DHS [22], the Secretariat of the Pacific Community (SPC) [23] and through general internet searches.
Available DHS reports were reviewed to identify all indicators relevant to: sexual activity, fertility and unintended pregnancy; contraceptive prevalence and unmet need for contraception; knowledge of family planning and exposure to family planning information; and problems accessing health services. Age-disaggregated data for each of these indicators were sought from the DHS reports to determine what information about adolescent women (aged 10-19 years) is accessible to policymakers and programmers. All reported data disaggregated by age were entered into an Excel [24] database to identify outcomes for adolescents and, where possible, compare with adult women for each country.

Data disaggregated by marital status in addition to age were also sought. However, while the surveys employ a standard methodology, the sampled population varies between countries, particularly in relation to eligibility for the "Women's Questionnaire" based on marital status. Some countries survey 'ever-married women' only, defined as women who are currently married or living in a consensual union and those who are divorced, widowed or separated. Other countries survey 'all women' including ever-married and unmarried women [22].

The review was limited to adolescent females, but it is acknowledged that many DHS also report outcomes for adolescent males for some indicators.

\section{Results}

DHS reports were available for eleven countries: Cambodia [25], Indonesia [26], Marshall Islands [27], Nauru [28], Papua New Guinea [29], Philippines [30], Samoa [31], Solomon Islands [32], Timor-Leste [33], Tuvalu [34] and Vietnam [35]. Thailand was excluded because the survey was conducted more than 20 years ago. Sampling periods of the DHS reports ranged from 1996 to 2009.

Forty relevant indicators were identified from the DHS reports (Table 1). Twenty seven of these were age-disaggregated to report data for women aged 15-19. No data were reported for adolescents aged 10-14. The number of countries reporting data for each indicator varied due to different survey methodologies, but age-disaggregated data were available for all countries for twelve indicators.

The inclusion of unmarried adolescents varied. Three of the eleven countries (Indonesia, Timor-Leste and Vietnam) sampled 'ever-married women' only. The remaining countries included unmarried adolescents in the sampled population, however, most data were reported for 'all women', combining both married and unmarried women and not allowing for comparisons between these two groups. Some indicators were only reported for currently married women despite 'all women' being sampled. Five of the 40 indicators were 
Table 1 Identified indicators from DHS reports

\begin{tabular}{|c|c|c|c|}
\hline $\begin{array}{l}\text { Indicators reporting data for } \\
\text { women aged } 15-19 \text { for all } \\
\text { countries }\end{array}$ & $\begin{array}{l}\text { Indicators reporting data for } \\
\text { women aged } 15-19 \text { for at least } \\
\text { one country }\end{array}$ & $\begin{array}{l}\text { Indicators reporting data for both married } \\
\text { and unmarried women aged } 15-19 \text { for at least } \\
\text { one country }\end{array}$ & $\begin{array}{l}\text { Indicators not reporting } \\
\text { data for women aged } \\
15-19\end{array}$ \\
\hline $\begin{array}{l}\text { Current marital status } \\
\text { Age at first marriage } \\
\text { Age-specific fertility rate } \\
\text { Trends in age-specific fertility } \\
\text { rate } \\
\text { Age first birth } \\
\text { Children ever born and living } \\
\text { Birth intervals } \\
\text { Teenage childbearing } \\
\text { Fertility planning } \\
\text { Ever use of contraception } \\
\text { Current use of contraception } \\
\text { Unmet and met need for } \\
\text { contraception }\end{array}$ & $\begin{array}{l}\text { Age at first } \\
\text { sex Recent sexual activity } \\
\text { Timing of first birth } \\
\text { Fertility preferences } \\
\text { Number of children at first use of } \\
\text { contraception } \\
\text { Quality of use/compliance with } \\
\text { contraception } \\
\text { Knowledge of contraceptive } \\
\text { methods } \\
\text { Knowledge of source of } \\
\text { contraception } \\
\text { Exposure to family planning } \\
\text { messages in the media } \\
\text { Exposure to family planning } \\
\text { messages through personal contact } \\
\text { Contact of non-users with family } \\
\text { planning providers } \\
\text { Discussion with husband/partner } \\
\text { about family planning } \\
\text { Husband/partners knowledge of } \\
\text { wife's use of family planning } \\
\text { Attitudes towards family planning } \\
\text { Problems accessing care }\end{array}$ & $\begin{array}{l}\text { Current marital status } \\
\text { Children ever born and living } \\
\text { Ever use of contraception } \\
\text { Current use of contraception } \\
\text { Unmet and met need for contraception }\end{array}$ & $\begin{array}{l}\text { Wanted fertility rate } \\
\text { Trends in contraceptive } \\
\text { use } \\
\text { Use of social marketing } \\
\text { brands } \\
\text { Source of contraception } \\
\text { Cost of contraception } \\
\text { Informed choice about } \\
\text { contraception } \\
\text { Problems with current } \\
\text { method } \\
\text { Discontinuation rate } \\
\text { Reasons for } \\
\text { discontinuation } \\
\text { Intended future use } \\
\text { Reasons for non-use } \\
\text { Preferred method } \\
\text { Knowledge of fertile } \\
\text { period }\end{array}$ \\
\hline
\end{tabular}

disaggregated by both age and marital status to demonstrate outcomes for unmarried adolescents. However, only four countries (Marshall Islands, Samoa, Solomon Islands and Tuvalu) reported data for unmarried adolescents for one or more of these indicators.

\section{Adolescent sexual activity, fertility and unintended pregnancy}

A significant proportion of women commence sexual activity during adolescence (Table 2). The median age of sexual debut for women aged 25-49 ranges from 17.3 to 21.9 years and is similar to age at first marriage. The proportion of women who commence sexual activity before the age of 15 varies considerably, from $0.5 \%$ in Tuvalu to $12.3 \%$ in Nauru. The proportion of adolescents who are currently sexually active (within the last four weeks) or have ever had sexual intercourse also varies considerably among countries that report data for 'all women'. Around half of adolescents in Marshall Islands, Nauru and Solomon Islands have ever had sex, and a considerable proportion commence sexual activity before the age of 15 years.

The median age of first birth ranges from 20.2 to 23.4 years. Between 3.4 and $26.3 \%$ of women aged $15-19$ are pregnant or have at least one previous birth (Table 3). By 19 years of age between 10.5 and $48.5 \%$ of adolescents have commenced childbearing (Figure 1). Adolescent fertility rates are high in most of the eleven countries, ranging from 25 to 138 births per 1000 women aged 15-19 years, and while they have declined in most countries compared with the 10 to 14 years preceding the survey, rates have remained relatively unchanged in Philippines, Samoa, Tuvalu and Vietnam, and have increased in Marshall Islands.

A significant proportion of births to adolescents are spaced less than 18 months apart. For the four countries that include data on women aged 15-19 for this indicator, 15.9 to $45.3 \%$ of adolescent births were separated by less than 18 months, the highest proportion of all age groups except in Timor-Leste (Figure 2).

Between 36.9 and $89.3 \%$ of pregnancies to adolescents are intended, or 'wanted now' (Figure 3). A significant proportion of adolescent pregnancies are mistimed or unwanted. In Marshall Islands, Nauru and Solomon Islands more than half of women aged 15-19 report that their last pregnancy was unintended. These countries also report the highest proportion of adolescents who have ever had sex relative to the proportion who are currently married.

\section{Current use and unmet need for contraception}

Current contraceptive prevalence, any method, among married adolescents varies greatly, ranging from 5.8 to $46.8 \%$, with the lowest use reported in Timor-Leste (Table 4). The majority of adolescents currently using contraception are using a modern method. However, a relatively large proportion of adolescents in Cambodia, Nauru, Papua New Guinea, Philippines, Solomon Islands and Vietnam are relying on traditional (and presumably less effective) methods. 
Table 2 Adolescent sexual activity - 'ever-married' and 'all women' (married and unmarried)

\begin{tabular}{|c|c|c|c|c|c|c|}
\hline Country and survey year & $\begin{array}{c}\text { Median age } \\
\text { first marriage, } \\
\text { females aged } \\
25-49 \text { (years) }\end{array}$ & $\begin{array}{l}\text { Proportion } \\
\text { females aged } \\
15-19 \text { currently } \\
\text { married }(\%)\end{array}$ & $\begin{array}{c}\text { Median age } \\
\text { sexual debut, } \\
\text { females aged } \\
25-49 \text { (years) }\end{array}$ & $\begin{array}{c}\text { Proportion } \\
\text { females aged } \\
25-49 \text { sexual debut } \\
<15 \text { years }(\%)\end{array}$ & $\begin{array}{c}\text { Proportion } \\
\text { females aged } \\
15-19 \text { currently } \\
\text { sexually active }(\%)\end{array}$ & $\begin{array}{c}\text { Proportion } \\
\text { females aged } \\
15-19 \text { ever } \\
\text { had sex }(\%)\end{array}$ \\
\hline \multicolumn{7}{|l|}{ 'Ever-married women' } \\
\hline Indonesia, 2007 & 19.8 & 12.8 & 19.7 & 1.3 & $n / a$ & $n / a$ \\
\hline Timor-Leste, 2003 & 21.4 & 11.2 & 20.7 & - & $n / a$ & $n / a$ \\
\hline Vietnam, 2002 & 21.1 & 4.1 & - & - & $n / a$ & $n / a$ \\
\hline \multicolumn{7}{|l|}{ 'All women' } \\
\hline Cambodia, 2005 & 20.1 & 9.8 & 20.4 & 2.0 & 8.3 & 10.8 \\
\hline Marshall Islands, 2007 & 19.6 & 1.2 & 17.3 & 11.6 & 29.3 & 64.5 \\
\hline Nauru, 2007 & 21.2 & 6.3 & 17.9 & 12.3 & 23.4 & 49.0 \\
\hline Papua New Guinea, 1996 & 19.9 & 18.2 & - & - & - & - \\
\hline Philippines, 2003 & 22.0 & 3.9 & 21.9 & 3.0 & 6.7 & 10.1 \\
\hline Samoa, 2009 & $23.6 \neq$ & 2.7 & - & - & - & - \\
\hline Solomon Islands, 2007 & 19.9 & 9.7 & 18.2 & 12.1 & 21.2 & 51.9 \\
\hline Tuvalu, 2007 & 22.1 & 8.0 & $21.7+$ & 0.5 & 9.1 & 14.2 \\
\hline
\end{tabular}

†Includes women aged 20-49

¥Samoa reports 'Singulate Mean Age at Marriage'

Current use of contraception is considerably lower among 'all women' (combining both married and unmarried adolescent women) compared with married women for those countries that report data for both groups. Marshall Islands, Nauru, Solomon Islands and Tuvalu also report contraceptive use for unmarried sexually active women, but only Marshall Islands and Solomon Islands report these data for adolescents: current use of any method for sexually active unmarried adolescents is $14.1 \%$ in Marshall Islands and $21.5 \%$ in Solomon Islands. Ninety and $65.6 \%$ of these women respectively are using a modern method.
In all countries with data, the contraceptive prevalence (any, modern and traditional methods) is lowest for married adolescents compared with adults, except for women aged 45-49 (Figure 4). This age-related trend is also observable for data reported for 'all women' or unmarried sexually active women.

Low contraceptive prevalence may reflect a desire to become pregnant or an inability to access family planning, resulting in an unmet need for contraception. A woman is considered to have an unmet need if she is of reproductive age and able to become pregnant, is married or in a consensual union, wants to limit or delay

Table 3 Adolescent fertility - 'ever-married' and 'all women' (married and unmarried)

\begin{tabular}{|c|c|c|c|c|}
\hline Country and survey year & $\begin{array}{c}\text { Proportion females aged 15- } \\
19 \text { who have commenced } \\
\text { childbearing (\%) }\end{array}$ & $\begin{array}{l}\text { Median age first } \\
\text { birth females aged } \\
25-49 \text { (years) }\end{array}$ & $\begin{array}{c}\text { Adolescent fertility rate } \\
\text { (births per } 1000 \text { women } \\
\text { aged 15-19) }\end{array}$ & $\begin{array}{l}\text { Adolescent fertility rate in } \\
\text { the } 10 \text { to } 14 \text { years } \\
\text { preceding the survey }\end{array}$ \\
\hline \multicolumn{5}{|l|}{ 'Ever-married women' } \\
\hline Indonesia, 2007 & 8.5 & 21.5 & 51.0 & 67.0 \\
\hline Timor-Leste, 2003 & 14.5 & $23.0+$ & 78.3 & $105.0 \neq$ \\
\hline Vietnam, 2002 & 3.4 & 22.7 & 25.0 & $20.0^{*}$ \\
\hline \multicolumn{5}{|l|}{ 'All women' } \\
\hline Cambodia, 2005 & 7.8 & 22.0 & 47.0 & 85.0 \\
\hline Marshall Islands, 2007 & 26.3 & 20.2 & 138.0 & 105.0 \\
\hline Nauru, 2007 & 15.0 & 21.9 & 69.0 & 101.0 \\
\hline Papua New Guinea, 1996 & 13.8 & 21.0 & 77.0 & 104.0 \\
\hline Philippines, 2003 & 8.0 & 23.2 & 53.0 & 66.0 \\
\hline Samoa, 2009 & 9.4 & 23.4 & 44.0 & 50.0 \\
\hline Solomon Islands, 2007 & 11.9 & 21.1 & 67.0 & 95.0 \\
\hline Tuvalu, 2007 & 8.0 & 23.1 & 42.0 & 34.0 \\
\hline
\end{tabular}

tIncludes women aged 20-49

$\neq 12-15$ years preceding survey

*ASFR reported in the $1987 \mathrm{DHS}$ 
pregnancy, and is not using a traditional or modern method of contraception. This includes women who are pregnant or have given birth in the last six months if the pregnancy was unintended [22]. Between 1.0 and $52.3 \%$ of married adolescents report an unmet need for contraception (Figure 5(a)). One to $49.9 \%$ of married adolescents also report an unmet need for birth spacing, that is they wish to delay their next pregnancy by two years or more but are not using any method of contraception (Figure 5(b)). Married women aged 15-19 have the highest unmet need of any age group in Indonesia, Marshall Islands, Philippines and Vietnam and among the highest unmet need in Cambodia, Samoa and Solomon Islands.

Some DHS also report source and cost of contraception, informed choice, problems with current method, reasons for and rate of discontinuation, intention for future use, reasons for non-use, and preferred methods. However, none of these indicators report data for women aged 15-19.

\section{Knowledge of family planning and access to information and services}

The percentage of women aged 15-19 (currently or 'ever-married') with knowledge of a modern method of contraception ranges from 31.1 to $99.4 \%$ (Figure 6(a)). In countries with overall high knowledge of modern contraception, the difference between adolescents and older women appears to be minimal. However, in settings where overall knowledge is lower, a greater proportion of adolescents than older women cannot recognise or name a modern method. Papua New Guinea and Timor-Leste also report knowledge of a source of family planning: 48.8 and $21.4 \%$ of married adolescents respectively know a source of contraception, the lowest of all age groups except for women aged 45-49 in Timor-Leste.

Between 10.9 and $84.8 \%$ of adolescents report that they have not seen or heard a family planning message in the media (including radio, television, newspaper/ magazine, poster or pamphlet) and the majority not using contraception have not discussed family planning with a health worker in the last 12 months (Figure 6(b) and $6(\mathrm{c})$ ). In most countries, a larger proportion of adolescents than women aged 20-29 have not discussed or been exposed to family planning information. In addition, between 55.2 and $97.4 \%$ of adolescents report at least one barrier to accessing health services, a greater proportion than women aged 20-34 (Figure 6(d)). Problems accessing care include financial barriers, poor geographical access, lack of knowledge of services and concerns about availability of health workers and commodities. Problems related to needing permission, not wanting to go alone and concern that there would be no female provider are particularly noted by adolescents compared with older women.

\section{Discussion}

DHS reports provide a large amount of useful information about adolescent fertility and family planning that is relevant to policymakers and programmers. All countries report data for adolescent fertility, contraceptive use and unmet need, and the majority also report data for adolescent sexual activity, knowledge and access to family planning information and services. However, DHS reports have been demonstrated to have some limitations [36]. These include the omission of young adolescents (10-14 years), the omission of unmarried adolescents or failure to report data for unmarried sexually active adolescents, and the failure to report age-disaggregated data for some important indicators, particularly contraceptive preferences and discontinuation. Data reporting broader sexual and reproductive health outcomes for adolescents, including sexually transmitted infections, HIV, and gender-based violence, are also required to inform comprehensive reproductive policy and programs. While beyond the scope of this review, the availability of these data in DHS reports has also been demonstrated to be limited [36].

\section{Unmarried adolescents}

The inability to determine outcomes for unmarried sexually active adolescents from the reported data is significant, particularly as some countries report a high prevalence of currently or ever sexually active adolescents in the context of a low prevalence of adolescent marriage. In general, the countries that include data for 'all women' (married and unmarried) report different outcomes to those that only include 'ever-married women', suggesting that unmarried adolescents' health outcomes and access to information and services differ to married adolescent women. Other studies have indicated that unmarried adolescents experience unique barriers to accessing reproductive health services and have different outcomes in relation to contraceptive use, unintended pregnancy and abortion [3-7], therefore their inclusion in reports of national-level surveys is vital.

\section{Adolescent sexual activity, fertility and unintended pregnancy}

A significant proportion of women commence sexual activity during adolescence. In the six countries that report data for 'all women' more than $10 \%$ of adolescents have ever had sex. In Marshall Islands, Nauru and Solomon Islands around half of adolescents have ever had sex, but less than $10 \%$ are married. Many adolescents, married and unmarried, are exposed to the risk of 


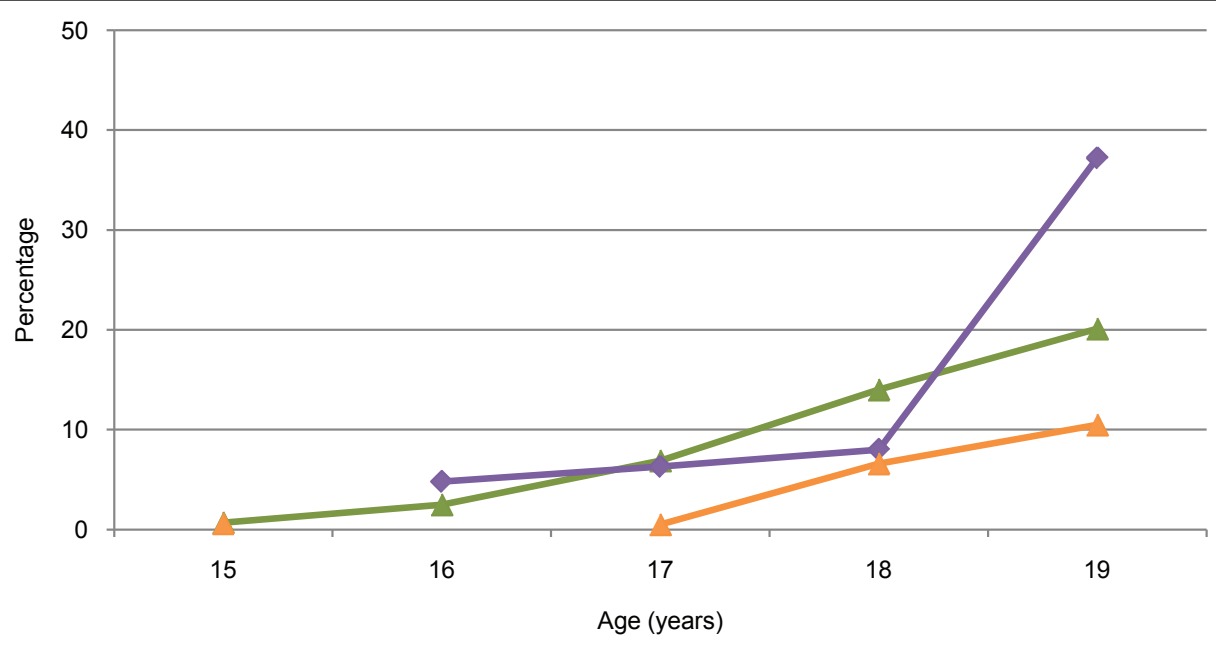

A
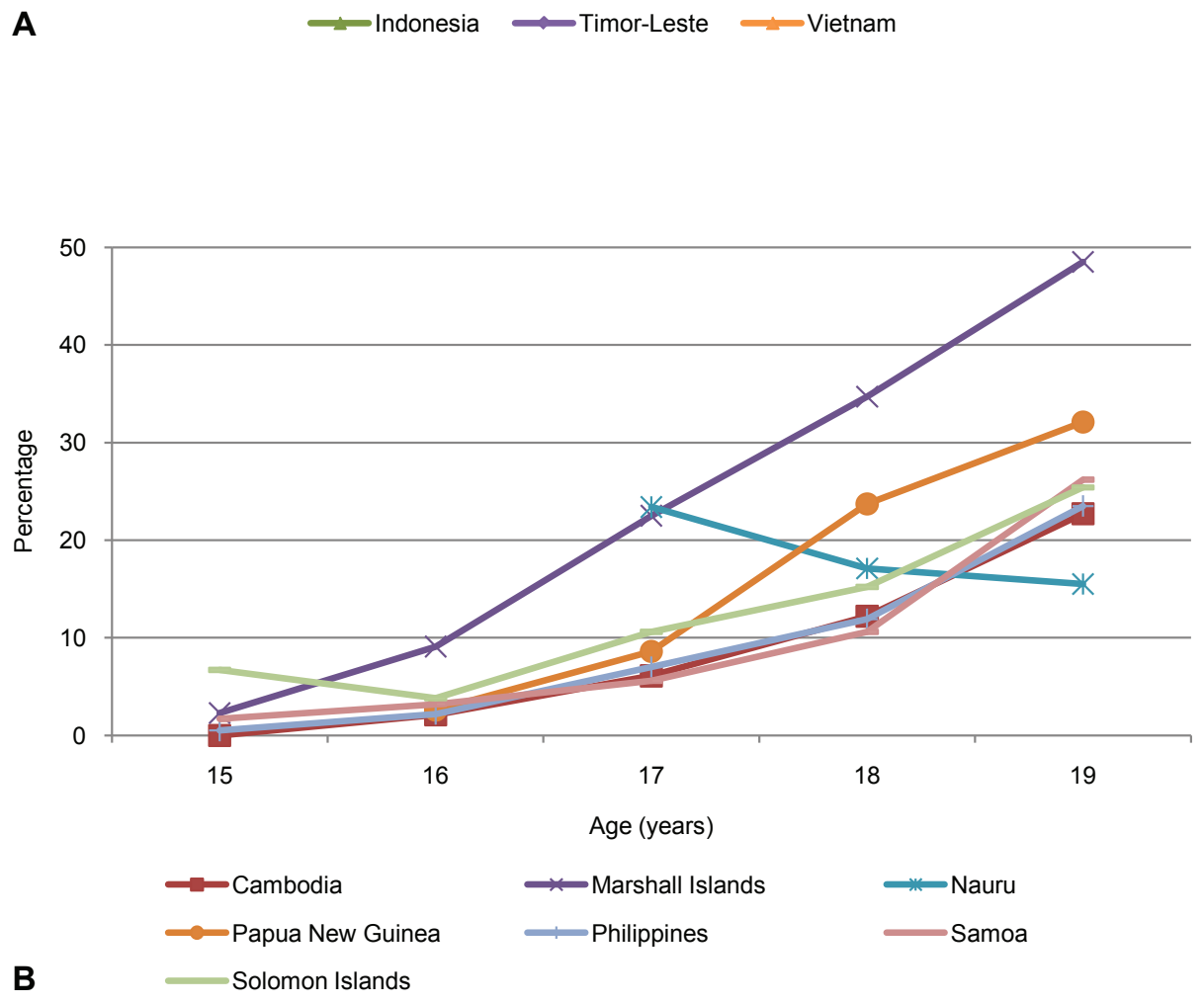

Figure 1 Proportion of women aged 15-19 who have commenced childbearing at age $x$ for A. 'ever-married women' and B. 'all women' (married and unmarried) (\%).

early pregnancy, highlighting the need for access to family planning information and services. Available data suggest this need is not being met, with a considerable proportion of adolescents commencing childbearing by the age of 19, a substantial number of adolescent births spaced less than 18 months apart, and a significant proportion of pregnancies unintended or unwanted.

A greater proportion of adolescent pregnancies are reportedly unwanted in countries that collect data for unmarried and married women compared with those that only include married women, particularly in those countries that report low adolescent marriage but high adolescent sexual activity. This could suggest that more unintended pregnancies occur among unmarried adolescents, although this was not able to be determined from the DHS reports due to the lack of data disaggregated by both age and marital status. An earlier review of adolescent childbearing in low income countries 


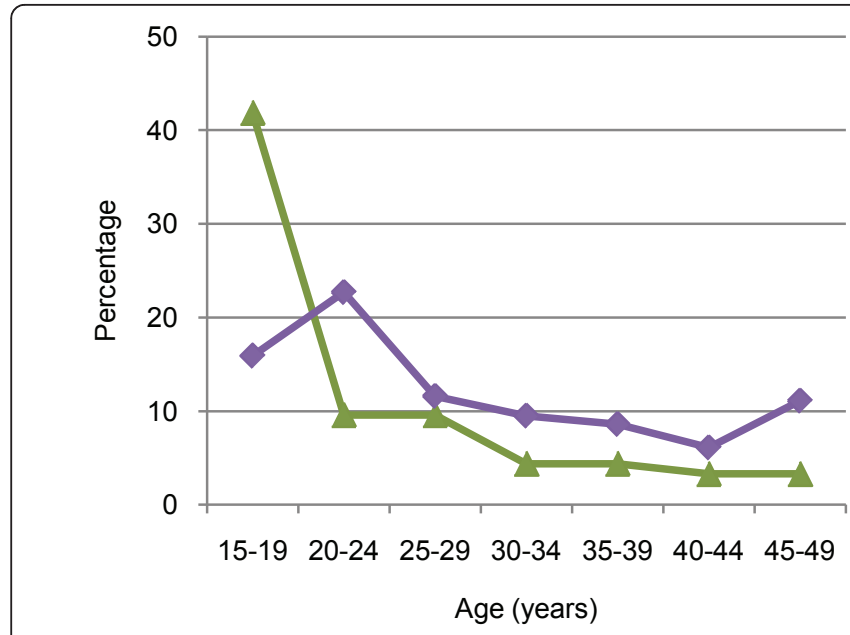

A $\quad \longrightarrow$ Indonesia $\quad$ Timor-Leste

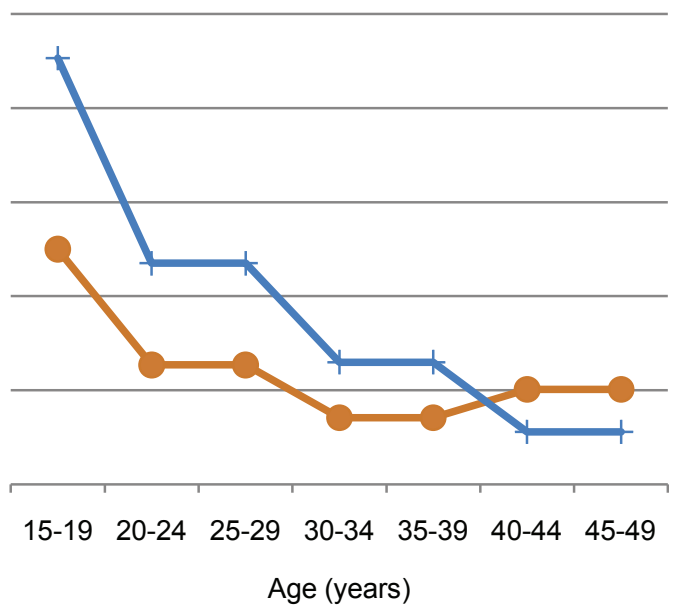

B $\longrightarrow$ Papua New Guinea $\longrightarrow$ Philippines

Figure 2 Proportion of births to women aged 15-49 spaced less than 18 months for A. 'ever-married women' and B. 'all women' (married and unmarried) (\%) Cambodia, Marshall Islands, Nauru, Samoa, Solomon Islands, Tuvalu and Vietnam do not include data for adolescents for this indicator because of too few non-first births in the 15-19 age group.

demonstrated that pregnancies to unmarried adolescents are much more likely to be unintended than married women [3], highlighting the need to report data for unmarried adolescents to inform policy and programs that aim to increase access to family planning.
Early pregnancy, intended or unintended, carries an increased risk of adverse health and socio-economic outcomes for women and their families and may result from poor access to information about family planning and the benefits of delaying first birth, poor access to

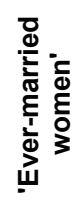

हั

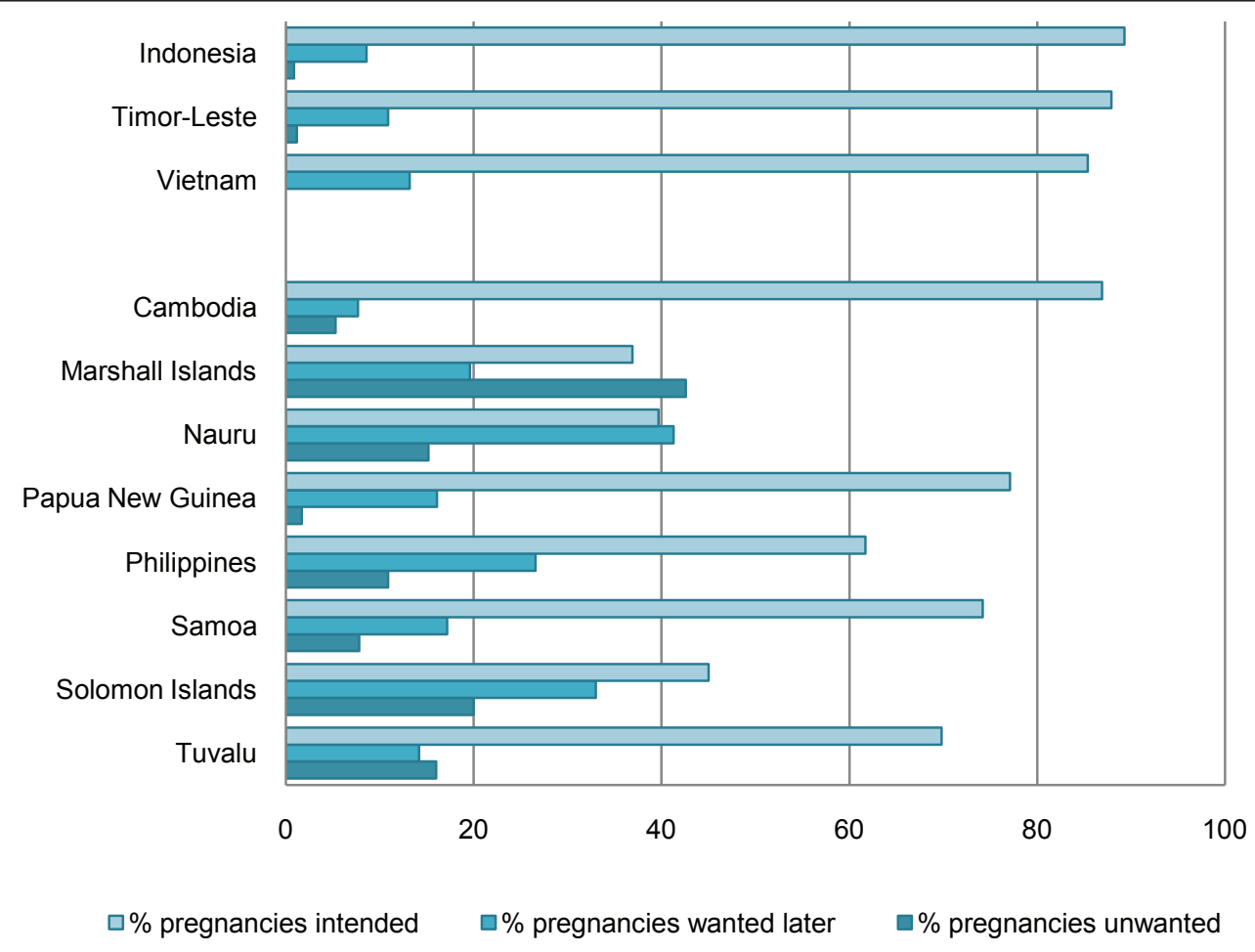

Figure 3 Proportion of pregnancies intended, mistimed or unwanted for 'ever-married' and 'all women' (married and unmarried) aged 15-19 (\%). 
Table 4 Percent distribution of current contraceptive use by method for currently married and 'all women' (married and unmarried) aged 15-19 (\%)

\begin{tabular}{|c|c|c|c|c|c|c|}
\hline \multirow[t]{2}{*}{ Country and survey year } & \multicolumn{2}{|c|}{ Any method } & \multicolumn{2}{|c|}{ Any modern method } & \multicolumn{2}{|c|}{ Any traditional method } \\
\hline & Currently married & 'All women' & Currently married & 'All women' & Currently married & 'All women' \\
\hline Cambodia, 2005 & 20.8 & 2.1 & 13.7 & 1.4 & 7.1 & 0.7 \\
\hline Indonesia, 2007 & 46.8 & - & 46.2 & - & 0.7 & - \\
\hline Marshall Islands, 2007 & 25.1 & 10.0 & 23.7 & 9.3 & 1.3 & 0.7 \\
\hline Nauru, 2007 & * & 8.5 & * & 3.8 & * & 4.7 \\
\hline Papua New Guinea, 1996 & 9.0 & 2.3 & 5.4 & 1.1 & 3.6 & 1.1 \\
\hline Philippines, 2003 & 25.6 & 2.4 & 13.2 & 1.3 & 12.3 & 1.1 \\
\hline Solomon Islands, 2007 & 19.5 & 7.2 & 12.8 & 5.2 & 6.7 & 2.1 \\
\hline Samoa, 2009 & 8.1 & 1.0 & 8.1 & 0.8 & 0.0 & 0.2 \\
\hline Timor-Leste, 2003 & 5.8 & - & 5.8 & - & 0.0 & - \\
\hline Tuvalu, 2007 & $*$ & 2.7 & * & 2.7 & * & 0.0 \\
\hline Vietnam, 2002 & 22.8 & - & 14.1 & - & 8.6 & - \\
\hline
\end{tabular}

* Figure not reported due to fewer than 25 cases

reproductive health services, and socio-cultural expectations of early marriage and childbearing. Further research is required to better understand the factors that influence early childbearing and contraceptive use among married and unmarried adolescents in East Asia and the Pacific and identify potential targets for intervention.

\section{Contraceptive use and unmet need}

The prevalence of modern methods of contraception among married adolescents is low in most countries. Low contraceptive use among young women is often considered to reflect a desire to become pregnant, particularly in settings where there is socio-cultural pressure to prove fertility $[7,12,37]$. However, the findings of this

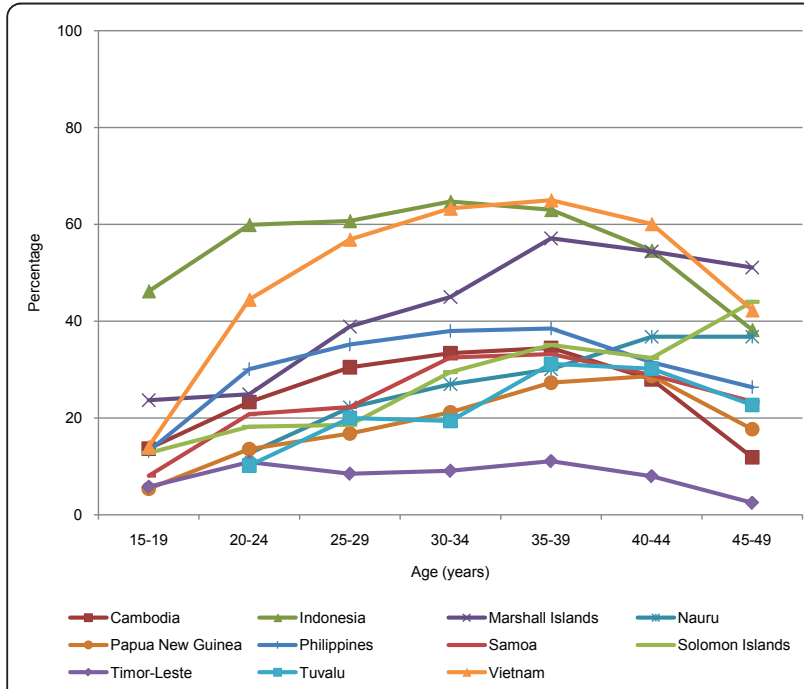

Figure 4 Current contraceptive prevalence, modern method, currently married women aged 15-49 (\%). review suggest that a significant proportion of married adolescents want to delay or space their pregnancies but are unable to do so. This includes women who have already proven their fertility, but still report a high unmet need for contraception to space their next birth. The reasons for this are likely to be complex, and may include socio-cultural factors or limited choice of appropriate and acceptable methods for birth-spacing [5], and require further investigation.

There is very little data on contraceptive use and unmet need among unmarried sexually active women. Contraceptive prevalence is considerably lower when all adolescents (regardless of marital status) are included. This suggests that a large proportion of unmarried adolescents are not using contraception, although it can't be determined what proportion of these are sexually active from the DHS reports. Only Marshall Islands and Solomon Islands report data for this group, and contraceptive prevalence is low among unmarried sexually active adolescents in both countries. Use of any method is lower than for married adolescents in Marshall Islands, but higher in Solomon Islands. Other studies have demonstrated that unmarried adolescents have different patterns of contraceptive use compared to married women, often reporting higher contraceptive prevalence but also higher unmet need and higher rates of discontinuation $[4,16,17,38]$. Further research is warranted to explore the context-specific reasons for low contraceptive use and discontinuation among both married and unmarried adolescents, and to identify preferred contraceptive methods.

\section{Knowledge and access to information and services}

Inadequate knowledge is one of the factors that contributes to low contraceptive use $[4,39,40]$. Married adolescents' knowledge of modern methods of contraception 

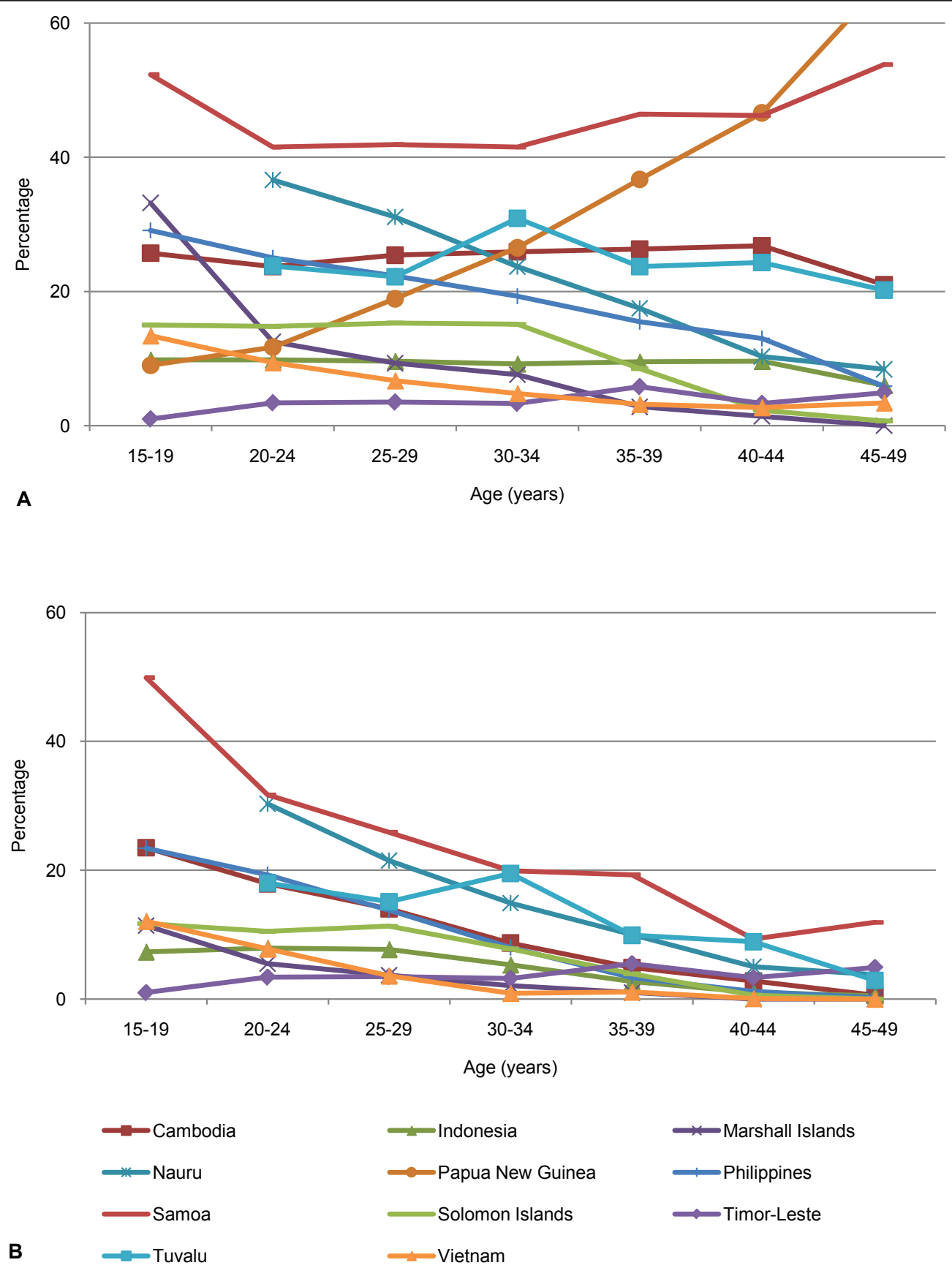

Figure 5 Proportion of currently married women aged 15-49 with A. unmet need for contraception and B. unmet need for birth spacing (\%) Nauru and Tuvalu do not report data for women aged 15-19 due to fewer than 25 cases.

varies considerably between countries, and is limited in some settings. Countries that report the lowest levels of knowledge, Timor-Leste, Samoa, Solomon Islands and Papua New Guinea, also report the lowest contraceptive prevalence among married adolescents. As many women commence sexual activity during adolescence, reproductive health information needs to be provided from an early age, with evidence suggesting that this can have life-long protective health effects $[39,41]$. The proportion of adolescents who have been exposed to family planning messages in the media also varies substantially, and is low in some countries. Delivering family planning information through mass media, in addition to other promotion efforts including referral to services, has been associated with an increase in contraception uptake [42], so appropriate channels to better reach adolescents need to be explored. 


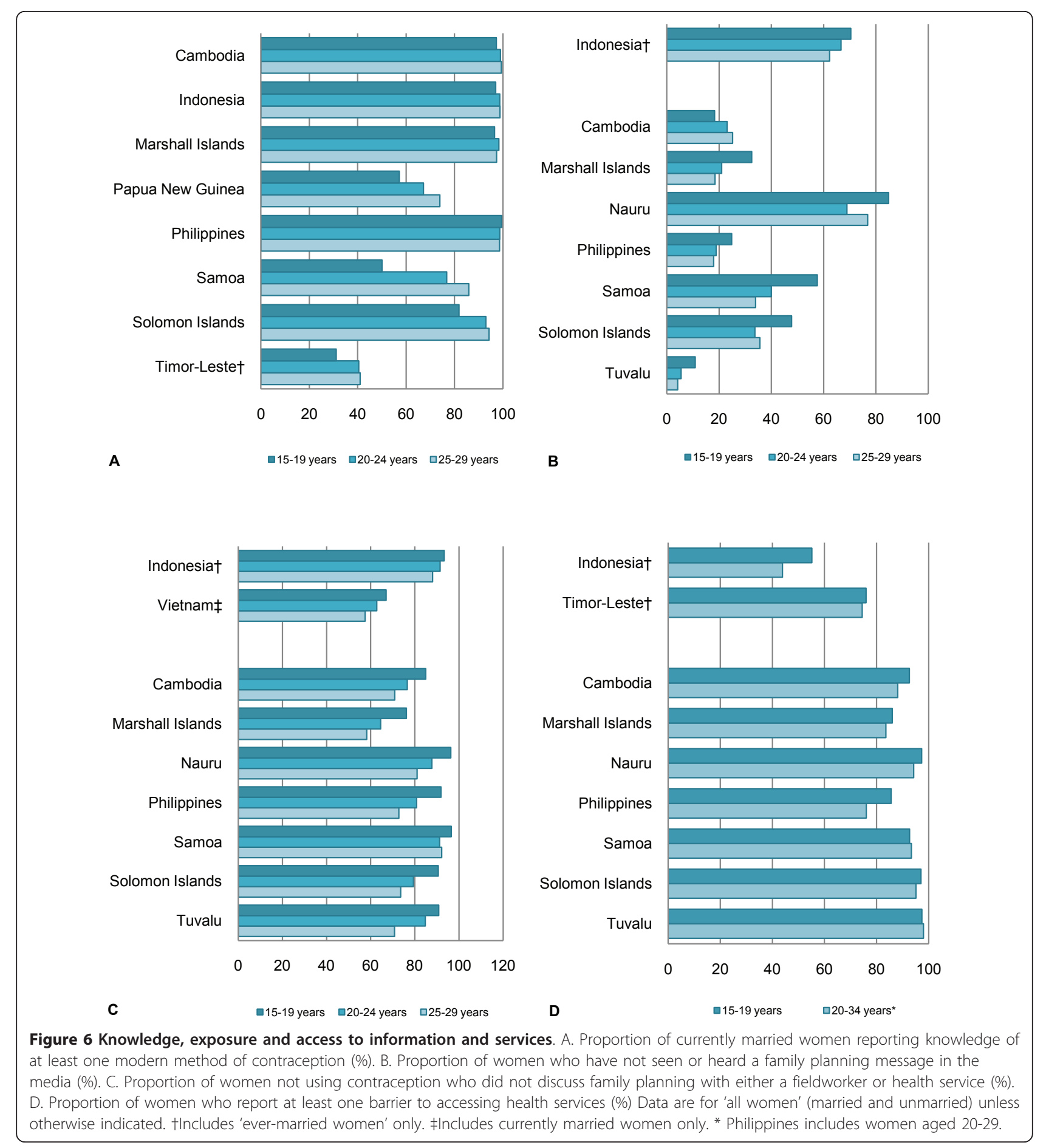

The majority of adolescents not using contraception have not discussed family planning with a health worker and a considerable proportion report at least one barrier to accessing health care. Adolescents face unique barriers to accessing reproductive health information and services, contributing to low contraceptive use in this age group [12]. These include lack of decision-making power and access to or control over resources, sociocultural norms regarding adolescent sexual behaviour and childbearing, and policy and legal restrictions $[39,40,43,44]$. The real and perceived skills, beliefs and attitudes of health workers can also affect the quality of information given to adolescents and their access to reproductive health services, including family planning 
$[45,46]$. Many of these factors are context-specific, highlighting the need for DHS data to be complemented by qualitative research. In addition, the information and service delivery preferences of adolescents require further investigation to identify how these barriers may be overcome.

\section{Adolescents compared with adult women}

In all eleven countries adolescents are less protected against unintended pregnancy than older women, with contraceptive use considerably lower in this age group than all others, except women over the age of 44. This is consistent with previous studies of contraceptive use in other low income countries [5,6]. In most countries adolescents also have higher unmet need for contraception, less knowledge, and poorer access to information and services than older women. These findings suggest that efforts to scale up reproductive health interventions, including increasing the uptake of family planning, do not necessarily reach adolescents and that targeted responses are required. While there is a growing body of evidence regarding youth-targeted programs to deliver reproductive health information and services $[12,47-49]$ there is a need to support more rigorous evaluations to identify effective approaches.

\section{Limitations}

This review has a number of limitations. Some surveys were conducted more than five to ten years ago and it is likely that adolescent fertility and contraceptive use have changed in that time. Only data available in DHS reports were included to reflect data readily accessible to policymakers and programmers. Analysis of primary data was beyond the scope of this review, however, further analysis is likely to yield useful information. This would be particularly relevant to those indicators not disaggregated by age, such as contraceptive preferences and discontinuation, as well as exploring outcomes for unmarried sexually active adolescents. In addition, sampling populations, survey questions and reporting of age-disaggregated data and marital status vary between countries for some indicators, limiting the ability to make country comparisons.

\section{Conclusion}

DHS reports provide much useful data accessible to policymakers and programmers; however they are limited by the failure to report data for unmarried sexually active adolescents or report age-disaggregated data for some indicators. Available data indicate that adolescent sexual activity and pregnancy are common in East Asia and the Pacific in the context of low contraceptive prevalence. Adolescents also appear to have lower use and higher unmet need for contraception, poorer knowledge of family planning and less access to information and services than older women.

The prevention of adolescent pregnancy is an integral component of efforts to improve maternal health and ensure universal access to reproductive health, but it cannot be assumed that adolescents will automatically benefit from policies and programs that are aimed at the general population. Further research is required to better understand the barriers that both married and unmarried adolescents face accessing reproductive health information and services, and their information and service delivery preferences, so that interventions can be effectively targeted to meet their needs. In addition, greater investment is needed to support rigorous evaluation of strategies that target adolescents so that effective approaches can be identified.

\section{Acknowledgements}

The authors would like to thank the many people involved in this review, particularly Elise Willersdorf for her assistance with the initial review design and Rachel Sacks-Davis for assistance with the database.

This review was funded by AusAID under the Knowledge Hubs for Health Initiative. Compass: the Women's and Children's Health Knowledge Hub is a collaboration between the Centre for International Health, Burnet Institute, the University of Melbourne's Centre for International Child Health, and Menzies School of Health Research, Darwin. The views presented here are those of the authors and do not represent any official position of AusAID or the Australian government.

\section{Author details}

'Centre for International Health, Burnet Institute, Melbourne Australia. ${ }^{2}$ Department of Epidemiology and Preventive Medicine, Monash University, Melbourne Australia. ${ }^{3}$ Centre for Adolescent Health, Royal Children's Hospital, Melbourne Australia.

\section{Authors' contributions}

NG and MC designed the initial review. EK, PA and NG reviewed the DHS reports and conducted the data entry and analysis. EK prepared the first draft of the paper. All authors made substantial comments and contributions to subsequent drafts and approved the final version submitted for publication.

\section{Competing interests}

The authors declare that they have no competing interests.

Received: 12 January 2011 Accepted: 5 May 2011 Published: 5 May 2011

\section{References}

1. Population Division, UN, World Population Prospects, 2008 Revision. (New York, 2009)

2. Guttmacher Institute, Facts on sexual and reproductive health of adolescent women in the developing world. In Brief. (New York, 2010)

3. S Singh, Adolescent childbearing in developing countries: a global review. Studies in Family Planning. 29, 117-136 (1998). doi:10.2307/172154

4. S Singh, J Darroch, L Ashford, M Vlassoff, Adding it up: The costs and benefits of investing in family planning and maternal and newborn health. (Guttmacher Institute and United Nations Population Fund. New York, 2009)

5. United Nations, World Population Monitoring 2002 - Reproductive rights and reproductive health: selected aspects. (Department of Economic and Social Affairs Population Division. New York, 2002)

6. AK Blanc, AA Way, Sexual behavior and contraceptive knowledge and use among adolescents in developing countries. Stud Fam Plan. 29, 106-16 (1998). doi:10.2307/172153

7. WHO, Adolescent pregnancy: unmet needs and undone deeds. (World Health Organisation. Geneva, 2006) 
8. $\mathrm{WHO}$, Why is giving special attention to adolescents important for achieving Millennium Development Goal 5? (World Health Organisation. Geneva, 2008)

9. GC Patton, C Coffey, SM Sawyer, RM Viner, DM Haller, K Bose., et al, Global patterns of mortality in young people: a systematic analysis of population health data. The Lancet. 374(9693):881-92 (2009). doi:10.1016/S0140-6736 (09)60741-8

10. I Shah, E Ahman, Age patterns of unsafe abortion in developing country regions. Reproductive Health Matters. 12(24):9-17 (2004). doi:10.1016/S09688080(04)24002-2

11. $\mathrm{WHO}$, Adolescent pregnancy. Issues in adolescent health and development. (World Health Organisation. Geneva, 2004)

12. LH Bearinger, RE Sieving, J Ferguson, S V, Global perspectives on the sexual and reproductive health of adolescents: patterns, prevention and potential. Lancet. 369, 1220-31 (2007). doi:10.1016/S0140-6736(07)60367-5

13. M Greene, T Merrick, Poverty Reduction: Does Reproductive Health Matter? World Bank Human Development Network, ed. Health, Nutrition and Population Discussion Papers. (The World Bank. Washington DC, 2005)

14. UNFPA, Briefing notes for Pacific Parliamentarians on population, development and reproductive health issues. (UNFPA Office for the Pacific Suva, 2007)

15. World Bank, Development and the Next Generation, World Development Report. (International Bank for Reconstruction and Development. Washington, DC, 2007)

16. AK Blanc, AO Tsui, TN Croft, JL Trevitt, Patterns and trends in adolescents' contraceptive use and discontinuation in developing countries and comparisons with adult women. International Perspectives on Sexual and Reproductive Health. 35(2):63-71 (2009). doi:10.1363/3506309

17. Khan Shane, Vinod Mishra, Youth Reproductive and Sexual Health. DHS Comparative Reports No. 19. (Calverton, Maryland, USA: Macro International Inc, 2008)

18. M Chan, M Kazatchkine, J Lob-Levyt, T Obaid, J Schweizer, M Sidibe., et al, Meeting the demand for results and accountability: a call for action on health data from eight global health agencies. PLoS Medicine/Public Library of Science.7(1):e1000223

19. GC Patton, RM Viner, C Linh le, S Ameratunga, AO Fatusi, BJ Ferguson, V Patel, Mapping a global agenda for adolescent health. J Adolesc Health. 47(5):427-32 (2010). doi:10.1016/j.jadohealth.2010.08.019

20. The World Bank, Country and lending groups.http://data.worldbank.org/ about/country-classifications/country-and-lending-groups

21. UNICEF, East Asia and the Pacific.http://www.unicef.org./infobycountry/ eastasia.html

22. Demographic and Health Surveys, Measure DHS.http://www.measuredhs com

23. Secretariat of the Pacific Community,http://www.spc.int/

24. Microsoft Office Excel 2007, (Microsoft Corporation, Redmond, Washington)

25. National Institute of Public Health, National Institute of Statistics (Cambodia), ORC Macro, Cambodia Demographic and Health Survey 2005 (Phnom Penh, Cambodia and Calverton, Maryland: National Institute of Public Health, National Institute of Statistics (Cambodia) and ORC Macro, 2006)

26. Statistics Indonesia (BPS), Macro International, Indonesia Demographic and Health Survey 2007. (Calverton, Maryland: BPS and Macro International, 2008)

27. Economic Policy, Planning and Statistics Office (EPPSO), SPC and Macro International Inc, Republic of the Marshall Islands Demographic and Health Survey 2007. (2007)

28. Nauru Bureau of Statistics, SPC and Macro International Inc, Nauru 2007 Demographic and Health Survey. (2007)

29. National Statistical Office Papua New Guinea, Papua New Guinea Demographic and Health Survey 1996: National Report. (Port Moresby: National Statistical Office Papua New Guinea, 1997)

30. National Statistics Office (NSO Philippines), ORC Macro, National Demographic and Health Survey 2003. (Calverton, Maryland: NSO and ORC Macro, 2004)

31. Ministry of Health (Samoa), Bureau of Statistics (Samoa), and ICF Macro, Samoa Demographic and Health Survey 2009. (Apia, Samoa: Ministry of Health, Samoa, 2010)

32. National Statistics Office (SISO), SPC, Macro International, Solomon Islands 2006-2007 Demographic and Health Survey. (Noumea: SPC, 2009)
33. Ministry of Health and National Statistics Office (Timor-Leste), University of Newcastle, Australian National University, ACIL Australia Pty Ltd, Timor-Leste 2003 Demographic and Health Survey. (Newcastle: University of Newcastle, Australia, 2004)

34. Central Statistics Division (TCSD), SPC and Macro International Inc, Tuvalu Demographic and Health Survey. (2007)

35. Committee for Population FaCV, ORC Macro, Vietnam Demographic and Health Survey 2002. (Calverton, Maryland: Committee for Population, Family and Children, and ORC Macro, 2003)

36. N Gray, P Azzopardi, E Kennedy, M Creati, E Willersdorf, Achieving MDG 5 for adolescents in Asia and the Pacific: lessons for the delivery of reproductive health services. Part 1: A review of available data in nine countries. (Burnet Institute on behalf of Compass, the Women's and Children's Health Knowledge Hub. Melbourne, Australia, 2010) http://www. wchknowledgehub.com.au

37. WHO, UNFPA, Married adolescents: no place of safety. (World Health Organisation. Geneva, 2006)

38. J Cleland, M Ali, I Shah, Trends in protective behavior among single versus married young women in Sub-Saharan Africa: the big picture. Reproductive Health Matters. 14(28):17-22 (2006). doi:10.1016/S0968-8080(06)28250-8

39. A Glasier, AM Gulmezoglu, GP Schmid, CG Moreno, PF Van Look, Sexual and reproductive health: a matter of life and death. Lancet. 368, 1595-607 (2006). doi:10.1016/S0140-6736(06)69478-6

40. Alan Guttmacher Institute, Into a new world: young women's sexual and reproductive lives. (Alan Guttmacher Institute. New York, 1998)

41. R Blum, K Mmari, Risk and protective factors affecting adolescent reproductive health in developing countries. (World Health Organisation. Geneva, 2004)

42. MA Wakefield, B Loken, RC Hornik, Use of mass media campaigns to change health behaviour. The Lancet. 376(9748):1261-71 (2010). doi:10.1016/S0140-6736(10)60809-4

43. CB Lloyd, BS Mensch, Marriage and childbirth as factors in dropping out from school: an analysis of DHS data from sub-Saharan Africa. Population Studies. 61(1):1-13 (2008)

44. S Singh, A Bankole, $V$ Woog, Evaluating the need for sex education in developing countries: sexual behaviour, knowledge of preventing sexually transmitted infections/HIV and unplanned pregnancy. Sex Educ. 5, 307-31 (2005)

45. CE Kaufman, T de Wet, J Stadler, Adolescent pregnancy and parenthood in South Africa. Stud Fam Plann. 32, 147-60 (2001). doi:10.1111/j.17284465.2001.00147.x

46. AC White, TW Merrick, AS Yazbeck, Reproductive Health: The Missing Millennium Development Goal. (World Bank. Washington DC, 2006)

47. International Planned Parenthood Federation Western Hemisphere Region (IPPF/WHR), Effective Strategies in Sexual and Reproductive Health Programs for Young People. (IPPF/WHR. New York, 2007)

48. Family Health International (FHI), YouthNet End of Program Report. Taking Action: Recommendations and Resources. (FHI. Arlington, VA, USA, 2006)

49. Family Health International (FHI), Evidence-based guidelines for youth peer education. (FHI. Arlington, VA, USA, 2010)

\section{doi:10.1186/1742-4755-8-11}

Cite this article as: Kennedy et al:: Adolescent fertility and family planning in East Asia and the Pacific: a review of DHS reports. Reproductive Health 2011 8:11.

\section{Submit your next manuscript to BioMed Central and take full advantage of:}

- Convenient online submission

- Thorough peer review

- No space constraints or color figure charges

- Immediate publication on acceptance

- Inclusion in PubMed, CAS, Scopus and Google Scholar

- Research which is freely available for redistribution

Submit your manuscript at www.biomedcentral.com/submit 